\title{
Diretrizes para a Normalização das Monografias, Dissertações e Teses do Programa de Pós-Graduação da Faculdade de Direito da Universidade Federal do Rio Grande do Sul
}

\author{
Naila Touguinha Lomando \\ Graduada em Biblioteconomia pela Faculdade de \\ Biblioteconomia e Comunicação da UFRGS. Bibliotecária da \\ Faculdade de Direito da UFRGS.
}

Simone Peixoto Maia

Graduada em Biblioteconomia pela Faculdade de Biblioteconomia e Comunicação da UFRGS. Ex-estagiária curricular da Biblioteca da Faculdade de Direito da UFRGS. 


\section{Resumo:}

O manual apresenta o conjunto de normas aplicáveis aos trabalhos de conclusão dos cursos de pós-graduação da Faculdade de Direito, da Universidade Federal do Rio Grande do Sul, incluindo comentários e exemplos. Descreve as partes dos documentos, enumerando os itens opcionais e obrigatórios que devem conter. Estabelece critérios de padronização para apresentação de monografias, dissertações e teses.

Palavras chaves: Normalização: Trabalhos acadêmicos 


\section{INTRODUÇÃO}

Este trabalho foi elaborado com o objetivo de oferecer aos alunos de Graduação, Especialização, Mestrado e Doutorado subsídios para a normalização de monografias, dissertações e. teses.

Está baseado nas normas da Associação Brasileira de Normas Técnicas (ABNT), sendo totalmente adaptado às exigências do Programa de Pósgraduação em Direito da Universidade Federal do Rio Grande do Sul, servindo, também, para o curso de Graduação da Faculdade de Direito da UFRGS.

\section{ESTRUTURA DO TRABALHO ACADÊMICO}

\subsection{Elementos Pré-textuais}

2.1.1 Capa (obrigatória): contém os elementos que identificam a obra, com a seguinte ordem (Anexo $A)$ :

a) instituição de ensino a que o autor está vinculado;

b) título principal do trabalho e subtítulo (se houver);

c) nome do autor;

d) local (cidade) da instituição onde deve ser apresentado;

e) ano da entrega.

2.1.2 Folha de Rosto (obrigatório): contém os elementos que identificam a obra, com a seguinte ordem, (Anexo B):

a) instituição de ensino a que o autor está vinculado;

b) título principal do trabalho e subtítulo (se houver);

c) nome do autor;

d) finalidade do trabalho e nome do orientador;

e) co-orientador (se houver);

f) local (cidade) da instituição onde deve ser apresentado;

g) ano da entrega

2.1.3 Errata (opcional): Consiste em uma lista que contém as follhas e linhas em que ocorreram os erros, seguidas de suas correções. Geralmente apresenta-se em papel avulso acrescido ao trabalho depois de pronto. Deve ser inserida após da folha de rosto e o texto deve estar disposto da seguinte maneira:

Página Linha Onde se lê Leia-se

2.1.4 Dedicatória (opcional): onde o autor dedica seu trabalho.

2.1.5 Agradecimentos (opcional): dirigidos à(s) pessoa(as) e/ou instituição(óes) que contribuíram de maneira relevante para a elaboração do trabalho 


\subsubsection{Resumo (obrigatório): na língua vernácula e em língua estrangeira.}

Resumo na língua vernácula: consiste na apresentação dos pontos relevantes do trabalho. $\mathrm{O}$ resumo deve dar uma visão clara do conteúdo e das conclusóes do trabalho. Deve ser redigido de forma objetiva e concisa, não devendo ultrapassar 500 palavras.

Resumo na língua estrangeira: consiste na versão do resumo em idioma de divulgạacão internacional (em inglês Abstract, em castelhano Resumem, em francês Résumé, por exemplo).

2.1.7 Sumário (obrigatório): enumeração das principais divisões, seções e partes. Feito na ordem em que as mesmas se sucedem no texto e acompanhado dos respectivos números das páginas. Havendo mais de um volume, em cada um deve constar o sumário completo. Inicia-se a partir da lista de ilustrações e localiza-se após a folha de rosto ou as folhas de dedicatória e agradecimentos quando houver. No sumário não devem constar as partes que o antecedem. (Anexo C)

2.1.8 Listas de Ilustrações (opcional): as figuras ou ilustrações devem ser relacionadas em lista à parte, devendo constar número, legenda e página para a sua localização.

2.1.9 Lista de Tabelas e Quadros (opcional): as tabelas e quadros devem ser relacionadas em lista à parte constando o número, o título e a página de sua localização.

2.1.10 Lista de Abreviaturas (opcional): lista em que se relacionam as abreviaturas e símbolos com seu respectivo significado. A ordenação é alfabética. (Anexo D)

\subsection{Elementos Textuais}

Parte do trabalho em que é exposta a matéria, contendo: introdução, corpo do trabalho (objetivos, revisão de literatura, metodologia) e conclusões.

\subsubsection{Introdução}

Parte inicial do trabalho onde deve ser delimitado o assunto abordado, os objetivos da pesquisa e os elementos que situem o tema.

\subsubsection{Corpo do trabalho}

Contém a exposição ordenada e pormenorizada dos assuntos. 


\subsubsection{Conclusão}

A conclusão é fundamentada no texto e constitui-se na síntese final do trabalho.

\subsection{Elementos Pós-textuais}

\subsubsection{Referências (obrigatório)}

A lista de referências bibliográficas é um conjunto de elementos que permite identificar as publicaçóes utilizadas, citadas ou não no decorrer do trabalho. São apresentadas em lista própria, ordenada alfabeticamente por sobrenome de autor e título. A lista de referências bibliográficas arrola somente documentos bibliográficos.

No caso de indicação de obras para aprofundamento do assunto, as mesmas deverão vir em lista separada, com o título Bibliografia Recomendada.

No caso de legislação e jurisprudência é aconselhável relacioná-las em listagem separada, ordenada alfabeticamente por local de abrangência, com o título Legislação e Jurisprudência Consultada e colocada imediatamente após a lista de referências bibliográficas.

A elaboração de referências bibliográficas será detalhada no capítulo 6 .

2.3.2 Apêndice (opcional) - texto elaborado pelo autor com a finalidade de complementar sua argumentação.

2.3.3 Anexos (opcional) - parte integrante do texto não elaborado pelo autor.

\section{APRESENTAÇÃO DOS ORIGINAIS}

\subsection{Generalidades}

Os textos devem ser apresentados através de documentos impressos, digitados em espaço 1,5, em papel A4, ocupando somente o anverso da folha.

\subsection{Paginação}

Todas as folhas do trabalho são contadas seqüencialmente a partir da folha de rosto. A folha de rosto, dedicatória, agradecimentos, epígrafe, resumo, abstract e folha inicial do sumário, bem como as páginas de início de capítulo, conclusão e referências não são numeradas. A numeração é colocada no canto superior direito, em algarismos arábicos. 


\subsection{Margem}

Margem esquerda: $4 \mathrm{~cm}$

Margem direita: $2 \mathrm{~cm}$

Margem inferior: $2 \mathrm{~cm}$

Margem superior: $3 \mathrm{~cm}$

Parágrafo: iniciar a $2,5 \mathrm{~cm}$ da margem esquerda

\subsection{Capítulo ou Seção}

Todos os capítulos devem ser iniciados em uma nova folha, mesmo que haja espaço na folha anterior.

Entre o título da seção anterior e o título da seção subsequente, e entre cada título devem-se observar dois espaços 1,5.

\subsection{Indicativo de Capítulo ou Seção}

O indicativo numérico de seção precede seu título, alinhado a esquerda, separado por um espaço de caractere. Nos títulos, sem indicativo numérico, como sumário, resumo, referência e outros devem ser centralizados.

\subsection{Numeração Progressiva}

A numeração progressiva é utilizada para evidenciar a sistematização do conteúdo do trabalho. Os títulos das seções são destacados gradativamente, utilizando-se negrito, itálico ou grifo, maiúsculas etc. Alguns Professores da Pós-Graduação em Direito adotam o Plano Francês, que consiste na divisão do trabalho em duas grandes partes, por meio de letras maiúsculas, subdividindoas, conforme a necessidade, em letras minúsculas.

\subsection{Formatação}

Usar, preferencialmente, Times New Roman ou Arial, com tamanho 12 para o texto, 11 para citações e 10 para as notas de rodapé.

\section{CITAÇÕES}

\subsection{Citação Direta ou Transcrição}

Citação direta são transcrições literais retiradas de textos consultados. 


\subsubsection{Citação com mais de três linhas}

Aparece em parágrafo separado, recuado a $4 \mathrm{~cm}$ da margem esquerda terminando na margem direita, com a mesma fonte, mas tamanho 11. Deve ser digitada em espaço simples, com espaço 1,5 entre a citação e os parágrafos anterior e posterior, sem aspas, seguida do nome do autor em letra maiúscula, uma parte do título e a página.

\section{Exemplo:}

O Constitucionalismo social paraguaio sofre, sem dúvida, alguma influência do Brasileiro, verificando-se algumas coincidências, como a restrição à sindicalização e greve das Forças Armadas e Policiais expressamente determinados, retendo, também muito da efetividade e concretização de seus dispositivos à lei infraconstitucional, inclusive a criação de órgãos e autoridades fiscalizadoras do comprimentos das normas laborais, o que sem dúvida, é uma avanço no sentido da dignificação do trabalho, do trabalhador, da justiça social e que merece apoio. (JUCÁ, A Constitucionalização..., p.96)

\subsubsection{Citação de até três linhas}

Deve ser inserida no texto entre aspas duplas. Se no texto já existir aspas, deve-se substituir por aspas simples. Seguida entre parênteses pelo sobrenome do autor (em letra maiúscula), parte do título e pela página, quando o autor não vier mencionado no texto.

\section{Exemplo:}

Alvim disse: "O termo 'individuais' aqui, como alhures se observa, deve ter sido usado sem sua adjetivação, 'homogêneos', por elipse, eis que conduziria à inconstitucionalidade [...]". (ALVIM, O Direito Processual..., p.120-121)

\subsection{Citação Indireta}

Citação indireta é a reprodução das idéias do autor sem transcrevê-las.

\section{Exemplo:}

Whetmore foi quem primeiro sugeriu que a sobrevivência seria impossivel se não buscassem alimentos dentre um deles, ou seja nos seus próprios corpos. (FULLER, O caso dos exploradores...,1976). 


\subsection{Citação de Citação}

É a menção de um documento ao qual se teve acesso, mas que se tornou conhecido apenas por citação em outro trabalho. Indica-se, primeiramente, o sobrenome do autor original seguido da expressão citado por ou apud e o sobrenome do autor da obra consultada, fazendo referência completa da obra consultada e esta constando da bibliografia.

\section{Exemplo:}

\section{MACHADO apud SILVEIRA, Introdução ao..., p.14}

\subsection{Citação de Jurisprudência}

Deve-se ao citar uma jurisprudência indicar, ao final da citação, entre parênteses, o país, estado ou município, corte ou tribunal, tipo e número do recurso, relator. A referência completa deverá constar no final do trabalho numa lista, à parte de legislação e jurisprudência consultada.

\section{Exemplo:}

Com efeito, a Constituição Federal de 1988, ao prever em seu art. 226, $3^{\circ}$, de que para efeito de proteção do Estado, é reconhecida a união estável entre o homem e a mulher como entidade familiar, não logrou equipará-la, para todos os efeitos, ao casamento. (SÃO PAULO, TJ. Ap. c/Ver. 544.013-00/ 11, Relator: Des. Manuel Ramos.).

\subsection{Citação de Legislação}

Citar uma legislação, indicando ao final da citação, entre parênteses, o país, estado ou município de onde ela se origina, seguido do número e especificação da legislação, data de publicação. Colocar a referência completa na lista de legislação e jurisprudência consultada.

\section{Exemplo:}

Como ressalta o artigo $4^{\circ}$ da Lei Orgânica dos Partidos Políticos: "A ação do partido será exercida, dentro de sue programa, em nome dos cidadãos que integram e sem vinculação com a ação de partidos ou governos estrangeiros". (BRASIL. Lei n $^{\circ} 4.740$, de 15 de julho de 1965.). 
4.6 Citação de Documentos Eletrônicos

A citação de documentos eletrônicos segue os mesmos padrões de citações de documentos impressos. Indique o responsável (país, entidades ou autor pessoal), seguido por uma parte do título, as páginas não são indicadas. A referência completa constará nas Referências no final do trabalho.

O sistema de chamada autor-data, no caso, autor-título, não é utilizado pela Pós-Graduação em Direito, mas as citações seguem o modelo apresentado acima, indicando o autor e título e página na nota de rodapé.

\section{NOTA DE RODAPÉ}

São anotações colocadas ao pé da página com a finalidade de esclarecer ou complementar o texto, sendo indicadas por números e/ou asteriscos.

Existem dois tipos de notas:

a) explicativa, consiste em uma explicação pertinente a uma palavra ou idéia;

b) bibliográfica, referência a um documento (livro, periódico) que tenha sido citado.

Nas notas de rodapé é comum o uso de termos, expressões latinas. Estas expressões só podem ser usadas quando fizerem referência às notas NA MESMA PÁGINA, OU EM PÁGINA CONFRONTANTE. É preferível repetir as indicações tantas vezes quanto se fizerem necessárias.

Na Pós-graduação em Direito, a indicação de autoria do texto é colocada em notas de rodapé, da seguinte forma:

REALE, Questões do direito..., p.23.

- Expressões Latinas

Apud (citado por): É usado quando um autor é citado por outro e não se tem o documento original. É a única expressão latina que pode ser usada também no texto.

Exemplo:

MACHADO, Introdução ao estudo...apud SILVEIRA, Teoria geral..., p.96. 
Ibidem ou Ibid. (na mesma obra): É usada quando o mesmo documento for citado várias vezes e mudar apenas a paginação. Só é usada quando as citações estiverem na mesma página do texto.

Exemplo:

REALE, Questões do direito..., p.23.

Ibidem, p.54.

Ibidem, p.234.

Idem ou Id. (mesmo autor): Usada quando forem citadas várias obras do mesmo autor, na mesma página do trabalho.

Exemplo:

DINIZ, Compêndio de introdução..., p.55.

Idem, Curso de direito..., p.66.

Idem, Princípios de direito..., p.192.

Não usar Idem Ibidem, o uso é redundante.

Op. cit. ou opere citato (na mesma obra): É usada quando se referir à obra citada pelo autor anteriormente, na mesma página, quando uma ou mais notas forem intercaladas.

MARQUES, Conflitos de leis..., p.125.

COSTA, O sistema da pose..., p.268.

MARQUES, op. cit., p.56.

Loc. cit. ou loco citato ( no lugar citado): É usado quando referir na mesma página de uma obra já citada, havendo intercalação de notas. Deve ser usada apenas na mesma página do trabalho.

Exemplo:

OLIVEIRA, Perfil dogimático..., p.54.

SANTOS, Da possibilidade..., p.135.

OLIVEIRA, loc. cit.

Et. seq. ou sequientia (seguinte ou o que segue): É usada quando não se menciona todas as páginas da obra. Indica-se a primeira página seguida da expressão et. seq. 
Exemplo:

MELLO, A aplicação do efeito..., p.249 et. seq.

Passim (aqui e ali): É usada para indicar as várias páginas de onde foram tiradas as citações, evitando a indicação repetitiva das páginas e indicando a página inicial e final.

\section{Exemplo:}

MEIRELLES, Direito administrativo..., p.34-67 passim

Obs. No editor de texto word o rodapé é colocado e numerado automaticamente, basta clicar em inserir e no menu de notas de rodapé.

IMPORTANTE: Quando a obra for mencionada pela primeira vez no texto, o rodapé deve conter a referência bibliográfica completa.

\section{REFERÊNCIAS}

Conjunto de elementos que permitem a identificação, no todo ou em parte, de documentos impressos ou registrados em diversos tipos de material.

\subsection{Lista Ordenada}

\subsubsection{Ordenação}

A ordenação pode ser alfabética, sistemática (assunto) ou cronológica. Recomenda-se a ordenação alfabética.

\subsubsection{Autor repetido}

Caso houver autor repetido nas obras, referenciado sucessivamente e na mesma página, o uso do travessão é facultativo nas referências seguintes.

\section{Exemplo:}

DINIZ, Maria Helena. Compêndio de introdução à ciência do direito. . Curso de direito civil brasileiro. 


\subsubsection{Título repetido}

O título de várias edições de um documento referenciado sucessivamente e na mesma página, é facultativo substituí-lo por travessão nas referências seguintes.

Exemplo:

RODRIGUES, Silvio. Direito civil. . 2.ed.

\subsection{Documentos Considerados no Todo}

\subsubsection{Livros e Folhetos de Autor Pessoal}

a) autor (com sobrenome em maiúsculo);

b) título (itálico, negrito ou sublinhado) e subtítulo, se importante;

c) edição;

d) local de publicaçầo, editora e data;

e) número de páginas ou volume;

f) série ou coleção (opcional);

g) notas especiais (opcional).

Exemplos

a) obras com um autor

MARQUES, Cláudia Lima. Contratos no código de defesa do consumidor. 3.ed.rev., atual e ampl. São Paulo: Revista dos Tribunais, 1998. (Biblioteca de Direito do Consumidor, 1 ).

b) obra com dois autores

LOUREIRO, Lair da Silva; LOUREIRO FILHO, Lair da Silva. Ação direta de inconstitucionalidade. São Paulo: Saraiva, 1996.

c) obra com três autores

DINIZ, Maria Helena; FERRAZ JÚNIOR, Tércio Sampaio; GEORGAKILAS, R. A. Stevenson. Constituição de 1988: legitimidade, vigência e eficácia, supremacia. São Paulo: Atlas, 1989. 
d) obra com mais de três autores

SÁ, Elizabeth Schneider de, et al. Manual de normalização de trabalhos técnicos científicos e culturais. 2.ed. Petrópolis: Vozes, 1996.

Obs. Utiliza-se a expressão latina et al. (et alii) para quando haver mais de três autores, indica-se somente o primeiro autor, seguida de et al.

e) organizador, coordenador, compilador etc.

Indicar a responsabilidade intelectual abreviada e entre parêntese após o nome do autor.

GIORGIS, José Carlos Teixeira (Org.) Inovações do código de processo civil. Porto Alegre: Livraria do Advogado, 1997.

\subsubsection{Dissertações e Teses}

a) autor (sobrenome em maiúsculo);

b) título (em itálico, negrito ou sublinhado) e subtítulo se importante;

c) local do curso (cidade), nome da universidade (abreviado), ano;

d) número de páginas ou volume (opcional);

e) indicação de dissertação ou tese, nome da faculdade e universidade por extenso e ano de conclusão.

Exemplos:

a) Dissertação

KINJINK, Danilo. A exceção de pré executividade. 1997. 271p. Dissertação (Mestrado em Direito) - Faculdade de Direito, Universidade Federal do Rio Grande do Sul, Porto Alegre.

b) Tese

COSTA, Judith Hofmeister Martins. Sistema e cláusula geral: a Boa-fé objetiva no processo obrigacional. 1996. 2v. Tese (Doutorado em Direito Civil) - Faculdade de Direito, Universidade de São Paulo, São Paulo.

6.2.4 Anais de Congressos, Seminários, Encontros (no todo) (cidade);

a) nome do evento (em maiúsculo), número e ano, local de realização 
b) título (itálico, negrito ou sublinhado);

c) local de publicação, editor, ano de publicação;

d) número de páginas ou volume (opcional).

Exemplo:

CONFERÊNCIA NACIONAL DA OAB, 23, 1990, Belo Horizonte. Anais... Brasília: OAB - Conselho Federal, 1990. 1022p.

6.3 Documentos Considerados em Parte

6.3.1 Partes sem Autoria Especial

a) autor (sobrenome em maiúsculo);

b) título (itálico, negrito, sublinhado) e subtítulo se importante;

c) edição;

d) local de publicação, editor, ano;

e) número de páginas ou volume(opcional);

f) localização da parte referenciada.

Exemplos:

a) volume com título

RODRIGUES, Sílvio. Direito civil. 15.ed. atual. São Paulo: Saraiva, 1997. v.4: Responsabilidade civil.

b) volume sem título

SOLAZZI, Siro. Scritti di diritto romano. Napoli: Eugene Jovene, 1957. 4 v. v. 2 .

c) capítulo do mesmo autor da obra no todo

MACHADO, Luiz Alberto. Introdução à teoria do crime. In: Direito criminal. São Paulo: Revista dos Tribunais, 1987. cap. 13. p. $\overline{77-85 .}$

6.3.2 Autor(es) Diferente(s) da Obra no Todo

a) autor do capítulo ou volume (sobrenome em maiúsculo);

b) título do capítulo ou volume; 
c) referência da publicação no todo precedida da expressão "In:" (quando houver título, colocar em itálico, negrito ou sublinhado, quando não houver autor, entrar pelo título com a primeira palavra dele em maiúsculo);

d) página inicial e final do capítulo.

Exemplos:

a) Anais (capítulo)

GRINOVER, Ada Pelegrine. A crise do poder judiciário. In: CONFERÊNCIA NACIONAL DA OAB, 23, 1990, Belo Horizonte. Anais... Brasília: OAB - Conselho Federal, 1990. p.179-187.
b) Capítulo

ZAVASCKI, Teori Albino. Medidas cautelares e medidas anteci-Patórias. In: GIORGIS, José Carlos Teixeira (Org.). Inovações do código de processo civil. Porto Alegre: Livraria do Advogado, 1997. p.23-46.

\subsubsection{Referências Legislativas}

\subsubsection{Constituições, Códigos, Coletâneas de Leis e Decretos}

a) local de abrangêencia dos códigos (país, estado, município) em maiúsculo;

b) nome e data no caso de constituições;

c) título (em itálico, negrito ou grifado);

d) edição;

e) local, editora e data;

f) número de páginas (opcional).

Exemplos:

BRASIL. Constituição, 1988. Constituição da República Federativa Brasil de 05 de outubro de 1988. 3.ed. São Paulo: Atlas, 1993. 204p.

BRASIL. Código de processo civil. 2.ed. rev. e atual. São Paulo: Revista dos Tribunais, 1997. 1065p. 


\subsubsection{Acórdãos, Decisões e Sentenças das Cortes ou Tribunais}

a) local de abrangência da jurisprudência (país, estado, município), em

maiúsculo;

b) nome da Corte ou Tribunal;

c) ementa ou acórdão;

d) tipo e número do recurso (agravo de instrumento, agravo de petição, apelação etc.)

e) partes litigantes;

f) nome do relator precedido da palavra "Relator";

g) data do acórdão, sempre que houver;

h) indicação da publicação que divulgou o acórdão.

\section{Exemplo:}

SÃO PAULO. Tribunal de Justiça. Demonstrado que o acidente ocorreu em razão de um buraco existente na via pública e provado o nexo causal com a incapacidade da vítima tem a Municipalidade o dever de pagar pensão, que à falta de prova de ganhos superiores, deve ficar limitada a 1 salário mínimo. Apelação cível 230.997-1/5. Municipalidade de Guarujá e Neuza Alves de Menezes. Relator: Desembargador Antônio Villen. 18 de outubro de 1995. Revista dos Tribunais, São Paulo, v.85, n.723, p. 676-678, jan. 1996.

\subsubsection{Leis, Decretos e Portarias}

a) local de abrangência da legislação (país, estado, município) em maiúsculo ou órgão legislador;

b) título (legislação, número e data);

c) ementa quando for o caso;

d) referência da publicação no todo, se livro, precedido de "In:" ou indicação dos dados do periódico, se revista ou jornal.

\section{Exemplos:}
a) Livro

BRASIL. Lei ${ }^{\circ}$ 6.514, de 22 de dezembro de 1977. Altera o Capítulo V do Título II da Consolidação das Leis do Trabalho, relativa à Segurança e Medicina do Trabalho. In: BRASIL. Segurança e medicina do trabalho. 25.ed. São Paulo: Atlas, 1994. 455p. p. 9-18. 


\section{b) Periódico}

BRASIL. Decreto n. 3.159, de $1^{\circ}$ de setembro de 1999. Altera dispositivo do Decreto de 21 de agosto de 1957, que cria o Conselho interministerial do Açúcar e do Álcool-CIMA e dá outras providências. Lex, São Paulo, v.63, p. 5208, set. 1999.

CONSELHO FEDERAL DE MEDICINA. Resolução n.1552, de 20 de agosto de 1999. Estabelece normas da CCIH para a prescrição de antibióticos nas unidades hospitalares. Lex, São Paulo, v. 63, p.5260-5261, set. 1999.

\subsubsection{Artigos de Periódicos}
a) autor do artigo em maiúsculo;
b) título do artigo e subtítulo (se necessário);
c) título do periódico (itálico, negrito, sublinhado);
d) título do fascículo, número especial e suplemento (se houver);
e) local de publicação;
f) volume e número;
g) página inicial e final do artigo;
h) mês ou equivalente (bimestre, trimestre, semestre, estação etc.);
i) ano de publicação.

\section{Exemplo:}

FRADERA, Véra Maria Jacob de. A circulação de modelos jurídicos europeus na América Latina: um entrave à integração econômica no Cone Sul? Revista dos Tribunais, São Paulo, v.86, n.736, p.20-39, fev. 1997.

\subsubsection{Artigos de Jornais}
a) autor do artigo em maiúsculo;
b) título e subtítulo;
c) título do jornal em itálico, negrito ou sublinhado;
d) local de publicação;
e) dia, mês e ano;
f) descrição física (número ou título do caderno, seção suplemento), páginas do artigo referenciado. 


\section{Exemplo}

COPETTI, Álvaro. Tumultos: anomia e crise social. Zero Hora, Porto Alegre, 14 dez. 1989. p.4.

6.4 Referências de Publicações Eletrônicas

6.4.1 Documentos que possuem autor
a) autor (sobrenome em maiúsculo);
b) título
c) disponibilidade e acesso;
d) data (dd mm aa)

Exemplo:

LUNELLI, Fábio Ricardo. Eutanásia Versus Direito de Morrer. Disponível em: <http://www.apriori.com.br/artigos/arti_26.htm. > Acesso em: 13 mar. 2000.

\subsubsection{Documento jurídico}

Indicar as informações conforme 6.3.3 acrescidas do endereço eletrônico e da data de acesso.

\section{Exemplo}

BRASIL. Lei n. ${ }^{\circ}$ 9.887, de 7 de dezembro de 1999. Altera a legislação tributária federal. Diário Oficial [da] República Federativa do Brasil. Brasília, DF, 8 dez. 1999. Disponível em: <http://www.in.gov.br/mp_leis/ leis_texto.asp?Id=LEI\%209887>. Acesso em : 22 dez. 1999.

Os documentos eletrônicos em geral, mesmo os trabalhos publicados em anais de congressos e seminários seguem as mesmas regras dos documentos em papel, acrescidos do endereço eletrônico e data de acesso. 


\section{REFERÊNCIAS BIBLIOGRÁFICAS}

1 - ASSOCIAÇÃO BRASILEIRA DE NORMAS TÉCNICAS. Apresentação de citações em documentos: NBR 10520. Rio de Janeiro: ABNT, 2001.

2 - ASSOCIAÇÃO BRASILEIRA DE NORMAS TÉCNICAS. Numeração progressiva das seções de um documento: NBR 6024. Rio de Janeiro: ABNT, 1990.

3 - ASSOCIAÇÃO BRASILEIRA DE NORMAS TÉCNICAS. Referências, elaboração: NBR 6023. Rio de Janeiro: ABNT, 2000.

4 - ASSOCIAÇÃO BRASILEIRA DE NORMAS TÉCNICAS. Resumos: NBR 6028. Rio de Janeiro: ABNT, 1990

5 - ASSOCIAÇÃO BRASILEIRA DE NORMAS TÉCNICAS. Sumário: NBR 6027. Rio de Janeiro: ABNT, 1990.

6 - ASSOCIAÇÃO BRASILEIRA DE NORMAS TÉCNICAS. Trabalhos acadêmicos, apresentação: NBR 14724. Rio de Janeiro: ABNT, 2001.

7 - CURTY, Marlene Gonçalves; CRUZ, Anamaria da Costa. Guia para apresentação de trabalhos acadêmicos, dissertações e tese. Maringá: Dentalpress, 2001.

8 - UNIVERSIDADE ESTADUAL PAULISTA. Coordenadoria Estadual de Bibliotecas. Editora UNESP. Normas para publicação da UNESP. São Paulo: Ed. da UNESP, 1994. 4 v. v. 4: Dissertações e teses: do trabalho científico ao livro.

9 - UNIVERSIDADE FEDERAL DO PARANÁ. Biblioteca Central. Normas para apresentação de trabalhos. 6.ed. Curitiba: Ed. da UFPR, 1996. 8v. vol. 7: Citações e notas de rodapé.

10 - UNIVERSIDADE FEDERAL DO PARANÁ. Biblioteca Central. Normas para apresentação de trabalhos. 6.ed. Curitiba: Ed. UFPR, 1996. 8 v. v.2: Teses, dissertações e trabalhos acadêmicos. 
ANEXO A - Capa

UNIVERSIDADE FEDERAL DO RIO GRANDE DO SUL

FACULDADE DE DIREITO

CURSO DE PÓS-GRADUAÇÃO EM DIREITO

A Proteção Jurídica dos Direitos da Personalidade da Pessoa Natural no Ordenamento Jurídico-constitucional Brasileiro

Sérgio Luiz Leal Rodrigues

Porto Alegre, 1998. 
ANEXO B - Folha de Rosto

\section{UNIVERSIDADE FEDERAL DO RIO GRANDE DO SUL FACULDADE DE DIREITO CURSO DE PÓS-GRADUAÇÃO EM DIREITO}

\section{A Proteção Jurídica dos Direitos da Personalidade da Pessoa Natural no Ordenamento Jurídico-constitucional Brasileiro}

Sérgio Luís Leal Rodrigues

Dissertação apresentada ao Programa de Pós-graduação em Direito, como requisito parcial para obtenção do grau de Mestre, sob orientação do prof. Luis Afonso Heck 


\section{SUMÁRIO}

INTRODUÇÃO

1 DAS RELAÇÕES DE COMPATIBILIDADE

1.1Princípio Dispositivo

1.2 Noções Preliminares

1.3 Fundamentos do Princípio Dispositivo

2 DAS RELAÇÕES DE COMPLEMENTARIEDADE

2.1 Princípio do Contraditório

2.2 Noções Preliminares

2.3 Conteúdo do Princípio do Contraditório

2.4 Igualdade entre as Partes 
ANEXO D - Lista de Abreviaturas e Siglas

\section{LISTA DE ABREVIATURAS E SIGLAS}

$\mathrm{CC}$

Código Civil

$\mathrm{CDC}$

Código de Defesa do Consumidor

CTN

Código Tributário Nacional

ONU

Organizações das Nações Unidas

UNCTAD Conferência das Nações Unidas sobre Comércio e Desenvolvimento 
Título em inglês:

Standartization directresses for monographs, dissertations and thesis from Post Graduation Program of Federal University from Rio Grande do Sul (UFRGS) Brazil, Faculty of Law

\section{Resumo em língua estrangeira:}

The manual presents the group of applicable norms to the works of conclusion of the courses of masters degree of University of Right, of the Federal University of Rio Grande do Sul, including comments and examples. It describes the parts of the documents, enumerating the optional and obligatory items that should contain. It establishes standardization criteria for presentation of monographs, dissertations and thesis.

Kay words: standartization directress 